\title{
3D-CFD Simulation of a GDI Injector Under Standard and Flashing Conditions
}

\author{
Simone Sparacino ${ }^{1,}{ }^{*}$, Fabio Berni ${ }^{1}$, Matteo Riccardi ${ }^{1}$, Andrea Cavicchi ${ }^{2}$, and Lucio \\ Postrioti $^{2}$
}

1 Dipartimento di Ingegneria “Enzo Ferrari”, Università di Modena e Reggio Emilia, Modena, Italy.

2 Dipartimento di Ingegneria, Università di Perugia, via Duranti 67, Perugia, 06125, Italy.

* Corresponding author: simone.sparacino@unimore.it

\begin{abstract}
In the optimization of GDI engines, fuel injection plays a crucial role since it can affect the combustion process and, thus, fuel efficiency and pollutant emissions. The challenging task is to obtain the required fuel distribution and atomization inside the combustion chamber over a wide range of engine operating conditions. To achieve such goals, flash-boiling can be exploited. Flash-boiling is a phenomenon occurring when fuel temperature exceeds saturation temperature or, similarly, when ambient pressure is lower than saturation one. Under these conditions, which can occur inside the injector or directly in the combustion chamber, the fuel undergoes extremely accelerated breakup and quickly evaporates. The proposed manuscript shows the application of an alternative flashboiling model, recently implemented by Siemens-PLM in STAR-CD V.2019.1, to be applied in 3D-CFD Lagrangian simulations of GDI sprays. Results are validated against experimental data, provided by the SprayLAB of the University of Perugia, on a single-hole research injector. The new flash-boiling model consists of three main parts: an atomization model able to compute droplet initial conditions and the overall spray cone angle; an evaporation model and, finally, a droplet break-up model; the last two models are designed to simulate all the physical events occurring when droplets are injected into the combustion chamber. As for the investigated operating condition, vessel pressure and temperature are $40 \mathrm{kPa}$ and $293 \mathrm{~K}$, respectively; as for the fuel (n-Heptane) temperature, it ranges from 303.15 $\mathrm{K}$ to $393.15 \mathrm{~K}$, on equal injection pressure $(10 \mathrm{MPa})$. The numericalexperimental comparison is carried out in terms of liquid penetration, imaging, and droplet sizing.
\end{abstract}

\section{INTRODUCTION}

In the last decade, besides the increasing level of hybridization [1], many efforts have been dedicated to increase the efficiency of the internal combustion engine while decreasing tailpipe emissions. As for spark ignition engines, the reduction of the specific fuel consumption is mainly limited by abnormal combustion onset. Therefore, attention of 
engine manufacturers is primarily focused on knock mitigation by means of several techniques such as improved cooling [2], adoption of a variable compression ratio [3], bore reduction [4], use of cooled EGR [5] and water (or water/methanol) injection [6-9], unconventional valve strategies [10] and, finally, Gasoline Direct Injection (GDI) systems [11]. In this panorama, a crucial role is played by CFD analyses which allow to reduce time- and cost-to-market thanks to a proper prediction of the knock onset. Simulations are based, on the one hand, on reliable knock models [12-16] and, on the other hand, on a robust numerical framework able to fairly reproduce flow field, cycle-to-cycle variability, heat transfer, spray, film formation, fuel chemistry and combustion [17-28].

As for GDI systems, besides a knock tendency reduction via the cooling effect of the mixture, they allow the adoption of a stratified charge which leads to a reduction of the specific fuel consumption at part-load and low revving speed conditions. A stratified charge is usually obtained by means of late injections [29], which in turn are feasible thanks to the remarkable injection pressures promoted by GDI systems. In fact, a higher injection pressure promotes a stronger spray break-up. Alternatively, to promote break-up and, hence, evaporation of the spray, injection can be carried out under flash boiling conditions.

Flash boiling occurs when fuel is injected in an ambient characterized by a static pressure lower than the fuel saturation pressure for a given temperature and it causes instability of the fluid operating under superheated conditions. The rapid reduction in pressure or the increase in superheat cause the fuel to enter a metastable state with a significant superheated thermal energy, which is absorbed via the rapid flash-boiling process. As a result, a fast vapor nucleation inside the liquid takes place; during the injection process the vapor bubbles grow up and burst due to the liquid pressure sudden drop from the nozzle to the ambient level. Flash boiling can occur inside the nozzle where the gaseous phase creates an under-expanded jet of fuel vapor at the nozzle exit, together with liquid droplets. This occurs due to the high injection pressure typically used with gasoline direct injection. In fact, in Gasoline Direct Injection engines operating under part load and early injection conditions, the in-cylinder pressure can fall below the atmospheric level at the start of the injection [30], while temperature can raise due to the presence of EGR. Spray morphology and air-fuel mixing are strongly influenced by the flash boiling phenomenon, and the effect of different injector configurations with different types of fluid on flash boiling were explored [31-37].

In this work, a flash boiling model recently implemented in STAR-CD V.2019.1 [38] is tested and validated against experimental data provided by the SprayLAB of Perugia University. A single-hole research injector is analyzed in a constant volume chamber characterized by a pressure of $40 \mathrm{kPa}$, in order to replicate an engine part-load operation. To evaluate the effect of the fuel (n-Heptane) temperature on the flash boiling phenomenon, two different conditions are investigated: a subcooled one and a flashing one, with injection temperatures equal to $303.15 \mathrm{~K}$ and $393.15 \mathrm{~K}$, respectively. The numerical framework is based on the Arbitrary Lagrangian-Eulerian (ALE) approach, in which computational parcels are introduced directly at the nozzle exit, hence the choice of droplet initial conditions is extremely important to achieve fully representative simulations of the spray [39]. Numerical simulations are validated against experimental data in terms of imaging, liquid penetration curves, and Phase Doppler Anemometry (PDA) data. In the paper, a methodology to evaluate droplet initial conditions from experimental momentum measurements is firstly presented. Secondly, a detailed description of the new flash boiling model is carried out. Thirdly results on both subcooled and flashing condition are discussed. Finally, conclusions on the present work are outlined. 


\section{A METHODOLOGY FOR DROPLET INITIALIZATION}

Evaluation of droplet initial conditions, in terms of diameter and velocity, is a crucial aspect in the ALE approach. Droplet characteristics at the nozzle exit have a large impact on spray penetration and morphology, as well as on the distribution of diameters and velocities along the envelope of the jet. A possible approach to evaluate droplet initial conditions involves Eulerian Multiphase nozzle internal flow simulations, as described in [40-41]. Since the internal nozzle geometry was not available for the investigated injector, an alternative approach developed at the SprayLAB of the University of Perugia was exploited, which is based on experimental momentum measurements as described in [4243]. The global spray momentum flux measurement is a widely diffused technique to understand the characteristics of the fuel flow. The total momentum flux is measured through the evaluation of the jet impact force on a target flat surface, located at a given distance from the injector tip.

$$
\dot{M}=F
$$

Definitions of both the momentum flux $\dot{M}$ and the mass flux $\dot{m}$ at the nozzle exit are reported in equations (2) and (3), where $\rho$ is the fuel density, $A_{e f}$ is the effective area and $v_{\text {eff }}$ the effective injection velocity:

$$
\begin{aligned}
& \dot{M}=\rho A_{e f f} v_{e f f}^{2} \\
& \dot{m}=\rho A_{e f f} v_{e f f}
\end{aligned}
$$

With traditional injector analyzers it is possible to evaluate the mass flux $\dot{m}$. To calculate the effective area, it is necessary to estimate the contraction coefficient $C_{A}$ defined as the ratio between $A_{\text {eff }}$ and the geometric area of the nozzle $A_{0}$. Combining equations (2) and (3) it is possible to write the $C_{A}$ coefficient as:

$$
C_{A}=\frac{\dot{m}^{2}}{\rho A_{0} \dot{M}}
$$

Then from the mass flux it is possible to calculate the discharge coefficient $C_{d}$ defined as:

$$
\begin{gathered}
C_{d}=\frac{\dot{m}}{\dot{m}_{\text {theoric }}}= \\
A_{0} \sqrt{2\left(p_{\text {inj }}-p_{\text {amb }}\right) \rho}
\end{gathered}
$$

The effective injection velocity can be evaluated from the velocity coefficient $C_{v}$, which depends on the $C_{d}$ and $C_{a}$ as follow: 


$$
\begin{gathered}
C_{v}=\frac{C_{d}}{C_{a}} \\
v_{\text {eff }}=C_{v} v_{\text {theoric }}
\end{gathered}
$$

This approach, based on experimental outcomes, provides significant information used to initialize the droplets in the Lagrangian simulations through a simple blob model. The initial droplet velocity is calculated as in the equation (7), while initial droplet diameter $D_{e f f}$ is evaluated from the contraction coefficient and the geometric diameter $D_{\text {geom }}$ as follow:

$$
D_{e f f}=D_{g e o m} \sqrt{C_{a}}
$$

\section{A NOVEL FLASH BOILING MODEL}

In GDI engines, at specific conditions, flash boiling can occur both inside and outside the nozzles and it massively impacts spray characteristics. However, internal nozzle flow simulations via a Eulerian approach imply significant computational efforts and require detailed CAD geometry of the injector. To provide an accurate prediction of droplet characteristics at nozzle exit under flash boiling conditions, 0D submodels can be adopted. In STAR-CD, the flash boiling atomization and evaporation models developed by Price [44-45] are implemented in combination with the vapor bubble breakup model proposed by Senda [46]. The latter considers flash boiling effects on droplet breakup after injection.

\subsection{Flash boiling atomization model}

Experimental outcomes show that the amount of flash boiling is mainly determined by superheat degree $\Delta T_{S D}$, defined as:

$$
\Delta T_{S D}=T_{i n j}-T_{s a t, \infty}
$$

where $T_{i n j}$ is the injection temperature and $T_{\text {sat,o }}$ is the saturation temperature at ambient pressure. It is assumed that the flash boiling atomization model is activated when superheat rises above a predefined threshold value, for example $10 \mathrm{~K}$. When flash boiling occurs, the injected droplet velocity is obtained from:

$$
U_{e f f}=\frac{A_{n}}{\dot{m}}\left(P_{s}-P_{\infty}\right)+U_{v e n a}
$$

where $A_{n}$ is the nozzle area, $\dot{m}$ is the mass flow rate of injection, $P_{s}$ is the saturation pressure at the fuel injection temperature, and $P_{\infty}$ is the ambient pressure. The velocity at the vena contracta $U_{\text {vena }}$ is obtained from:

$$
U_{\text {vena }}=\frac{\dot{m}}{A_{n} \rho_{l} C_{c}}
$$


where $\rho_{l}$ is the density of the liquid, and $C_{c}$ is the contraction ratio defined as the ratio between the mean velocity and the $U_{v e n a}$. In this work $C_{c}$ is calculated with an empirical formula. The spray cone angle is modelled as [45]:

$$
\theta=a \beta^{2}+b \beta+c
$$

where $\beta$ is a non-dimensional parameter that depends on the ratio between the saturation pressure and the ambient pressure as well as on the surface tension of the fuel. In the equation (11), default values of the coefficients $a, b$ and $c$ are -3.208, 366.61 and 10324 respectively. At flash boiling conditions, vapour is generated inside the nozzle and the resulting volume flowrate $\dot{V}_{\text {vap }}$ is calculated as:

$$
\dot{V}_{\text {vap }}=N_{\text {nuc }} f V_{b} S_{\text {nozzle }}
$$

where $N_{\text {nuc }}$ is the nucleation site density per unit surface area, $V_{b}$ is the bubble departure volume, $f$ is the bubble departure frequency, and $S_{\text {nozzle }}$ is the inner surface area of the nozzle orifice. The liquid volume flowrate is calculated as:

$$
\dot{V}_{\text {liq }}=\dot{V}_{\text {total }}-\dot{V}_{v a p}
$$

Making the hypothesis that the liquid volume flowrate corresponds to the volume of the droplet exiting the nozzle, it is possible to evaluate the initial droplet diameter as:

$$
D_{d}=\left(\frac{6 \dot{V}_{l i q}}{\pi}\right)^{\frac{1}{3}}
$$

The flash boiling atomization model estimates the effective velocity of the droplets $U_{e f f}$, their diameter at the nozzle exit $D_{d}$, and the cone angle $\theta$ taking into account flash boiling effects such as vapor generation inside the nozzle and reduction of efflux section.

\subsection{Flash boiling evaporation model}

In addition to the mass transfer $\dot{m}_{s c}$ predicted by the standard evaporation model, driven by heat transfer from ambient gas to droplets, evaporation due to flash boiling is predicted with an additional term $\dot{m}_{s h}[44]$ :

$$
\begin{gathered}
\dot{m}_{s c}=A P \frac{S h D_{i}}{T_{f} R_{f} D_{d}} \ln \left(\frac{P-P_{v}}{P-P_{s}}\right) \\
\dot{m}_{s h}=\frac{A \alpha \Delta T_{S D}}{H_{l}}
\end{gathered}
$$

where $A$ is the droplet surface area, $P$ is the ambient pressure, $S h$ is the non-dimensional Sherwood number, $D_{i}$ is the binary diffusion coefficient, $T_{f}$ is the temperature of the vapor film, $R_{f}$ is the specific gas constant of the vapor film, $P_{v}$ is the partial vapor pressure in the cell, $P_{s}$ is the saturation pressure of the fuel, $H_{l}$ is the latent heat of vaporization, and $\alpha$ is the overall heat transfer coefficient given by empirical functions [47]: 


$$
\begin{aligned}
& \alpha=760 \Delta T_{S D}^{0.26} \text { if } 0 \\
& \leq \Delta T_{S D} \leq 5 \\
& \begin{array}{r}
\alpha=27 \Delta T_{S D}^{2.33} \text { if } 5 \\
\leq \Delta T_{S D} \leq 25
\end{array} \\
& \alpha=13800 \Delta T_{S D}^{0.39} \text { if } \Delta T_{S D} \geq 5
\end{aligned}
$$

\subsection{Flash boiling droplet breakup model}

Flash boiling can occur outside the nozzle as well, promoting droplet break-up and leading to significantly smaller droplets. In this paper the bubble nucleation and growth model of Senda [48] is adopted for the simulation of droplet breakup due to flash boiling occurring inside droplets outside of the nozzle. Firstly, bubbles are created through a nucleation process within the droplets, whose bubble number density $N$ is obtained from:

$$
N=C \exp \left(\frac{-\Delta A}{\Delta T_{S D}}\right)
$$

where $C$ and $\Delta A$ are model constants having values of $1.11 \times 1012$ and 5.28, respectively. Bubble growth is secondly modelled by solving the following equation:

$$
R \ddot{R}+\frac{3}{2} \dot{R}^{2}=\frac{1}{\rho}\left(P_{w}-P_{\infty}\right)
$$

and

$$
P_{w}=P_{S}+\left(P_{r 0}+\frac{2 \sigma}{R_{0}}\right)\left(\frac{R_{0}}{R}\right)^{3 n}-\frac{2 \sigma}{R}-\frac{4 \mu_{l} \dot{R}}{R}-\frac{4 k \dot{R}}{R^{2}}
$$

where $R$ is the bubble radius, $R_{0}$ is the initial bubble radius (with $10 \mu \mathrm{m}$ default value), $P_{\infty}$ is the ambient pressure, $P_{r 0}$ is the pressure at the nozzle orifice, $\mu_{l}$ is the liquid viscosity, $\sigma$ is the surface viscosity coefficient set by default to $1.25 \times 10-5 \mathrm{Ns} / \mathrm{m}$. Droplet breakup due to flash boiling only occurs when the bubble volume fraction $\varepsilon$ exceeds a threshold volume fraction $\varepsilon_{\max }$ set to 0.55 :

$$
\varepsilon=\frac{V_{\text {bubble }}}{V_{\text {bubble }}+V_{\text {liquid }}}>\varepsilon_{\text {max }}
$$

When droplet breakup occurs, the number of child droplets generated is taken as twice the number of bubbles. 


\section{OPERATING CONDITIONS AND NUMERICAL SETUP}

In this work a single-hole research injector is simulated under both standard and flashing conditions, with the aim to evaluate the new flash boiling model. The injector is characterized by a step-hole geometry, with a nominal orifice diameter equal to $175 \mu \mathrm{m}$. Operating conditions for both standard and flashing tests are reported in Table 1:

Table 1. Investigated operating condition

\begin{tabular}{ccc}
\hline Parameter & Subcooled Case & Flashing Case \\
\hline Fuel & n-Heptane & n-Heptane \\
Injection Pressure & $10 \mathrm{MPa}$ & $10 \mathrm{MPa}$ \\
Fuel Temperature & $303.15 \mathrm{~K}$ & $393.15 \mathrm{~K}$ \\
Vessel Pressure & $0.04 \mathrm{MPa}$ & $0.04 \mathrm{MPa}$ \\
Vessel Temperature & $293.15 \mathrm{~K}$ & $293.15 \mathrm{~K}$ \\
\hline
\end{tabular}

The computational domain for 3D-CFD simulations consists of a 70x70x160 mm blockshaped vessel. Numerical grid comprises hexahedral cells and it is characterized by a coneshaped refinement along the jet envelope, where minimum cell size is equal to $0.5 \mathrm{~mm}$ in order to obtain both a moderate computational cost and a reduced grid dependency [49].

As for the turbulence modeling a RANS approach is adopted in all the simulations and, specifically, the k- $\varepsilon$ RNG two-equation turbulence model [50] is adopted. A coupled Eulerian-Lagrangian approach is exploited to enable the numerical modeling of a dispersed multi-phase flow. The second order MARS numerical scheme is adopted for temperature, momentum, and turbulent quantities. In all the simulations 30 parcels are injected every time-step; this last is equal to $1 \mathrm{e}-6 \mathrm{~s}$ in order to keep the maximum Courant number well below unity. The computational domain is initialized with experimental pressure and temperature values, and all the boundaries are set as non-slip adiabatic wall. One singlecomponent fuel n-Heptane is injected, whose properties are inherited from the NIST database for both liquid and vapor phase [51].

In all the simulations the experimental injection mass flow rate profile, provided by the SprayLAB of Perugia University, is adopted. In the numerical framework the syringe-like effect described in [52] is considered in order to obtain a faithful numerical representation since the very early stage of the injection.

Primary break-up uses a simplified Blob Model, while for secondary break-up the Reitz-Diwakar model [53] is adopted; values of the model constants are calibrated in the subcooled case and then they are retained in the flashing one, with the aim to evaluate the reliability of the flash boiling breakup model contribution to the estimation of the reduction of droplet size due to bubbles burst inside the liquid droplets.

\section{NUMERICAL RESULTS}

In the subcooled case, droplet initialization is based on experimental momentum and mass flow rate outcomes, while at flashing conditions the flash boiling atomization model automatically evaluates droplet properties at the nozzle exit. As for the spray semi-cone angle, in the subcooled case it is imposed equal to $10 \mathrm{deg}$ according to the experimental imaging; for the flashing case, the semi-cone angle value is calculated by the flash boiling 
atomization model. Experimental tests are carried out with an injection pressure equal to 10 $\mathrm{MPa}$ and an excitation time equal to $1 \mathrm{~ms}$ for the momentum and $1.5 \mathrm{~ms}$ for the mass flow rate. Experimental curves are depicted in Fig.1

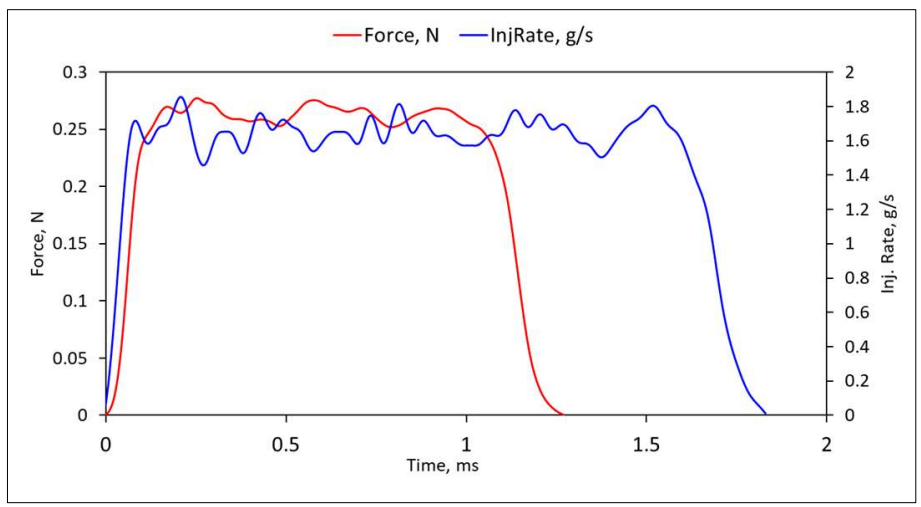

Fig. 1. Experimental mass flow rate and force provided by SprayLAB

The resulting hydraulic coefficients obtained with the previously described methodology are reported in Table 2:

Table 2. Estimated values for the injector hydraulic coefficients

\begin{tabular}{ll}
\hline $\mathrm{Ca}$ & 0.703 \\
$\mathrm{Cd}$ & 0.581 \\
$\mathrm{Cv}$ & 0.826 \\
\hline
\end{tabular}

A first comparison between experimental and numerical outcomes is carried out in terms of imaging. For the sake of brevity, only three snapshots are chosen and reported in Figs. 2 and 3.

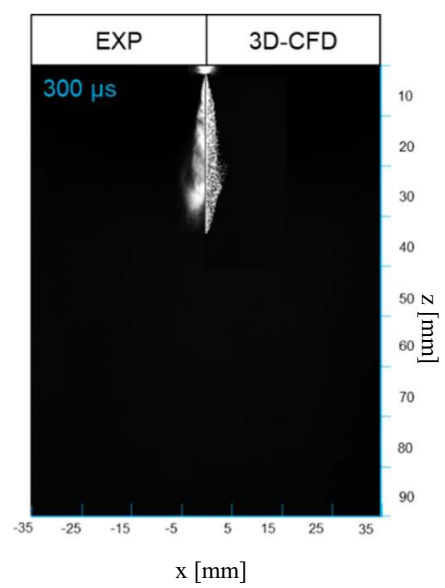

(a)

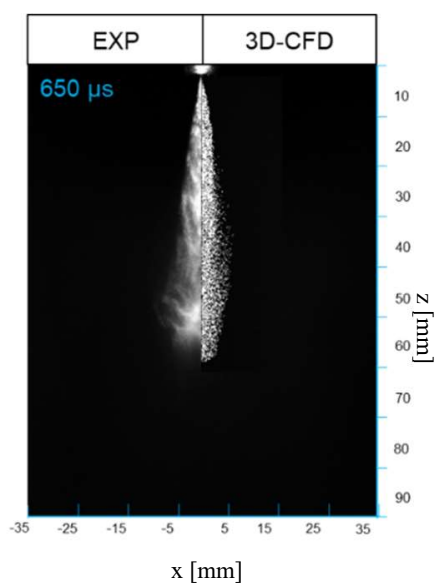

(b)

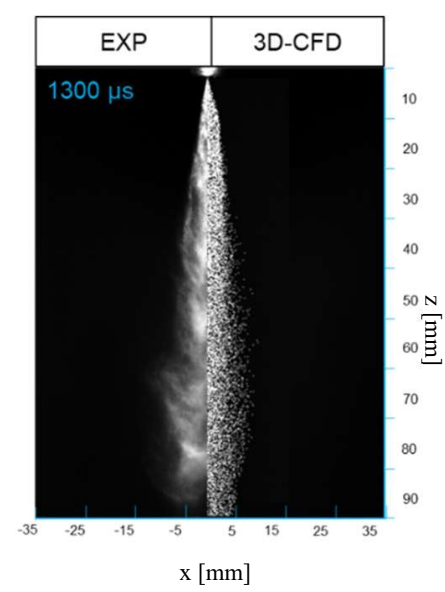

(c)

Fig. 2. Comparison in terms of imaging between experimental outcomes and numerical simulations at (a) $300 \mu \mathrm{s}$, (b) $650 \mu \mathrm{s}$, and (c) $1300 \mu \mathrm{s}$ after the start of injection at subcooled conditions. 


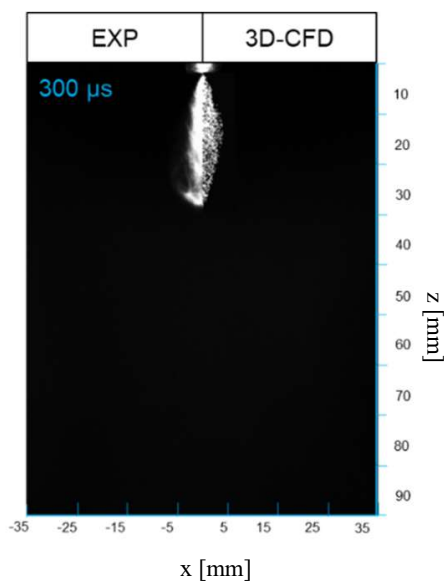

(a)

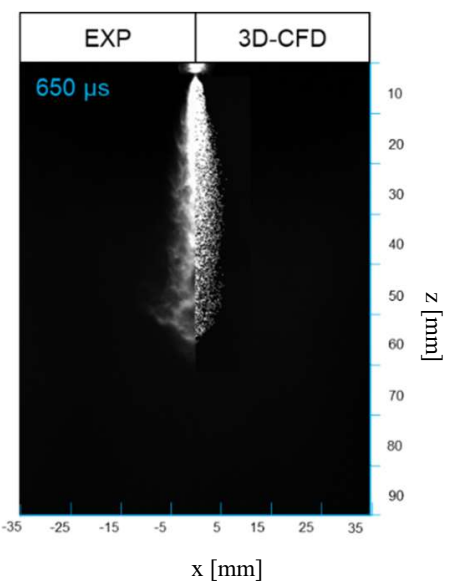

(b)

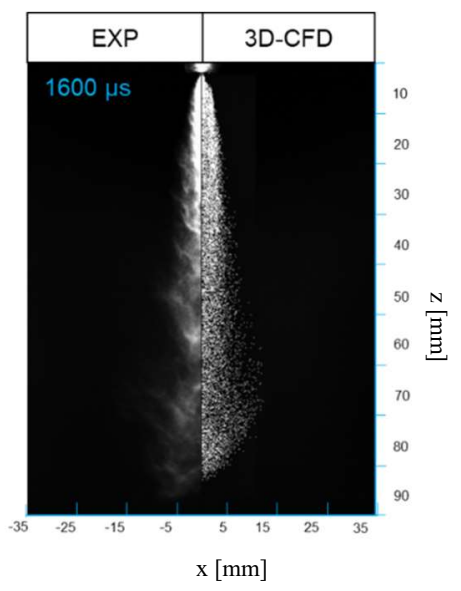

(c)

Fig. 3. Comparison in terms of imaging between experimental outcomes and numerical simulations at (a) $300 \mu \mathrm{s}$, (b) $650 \mu \mathrm{s}$, and (c) $1600 \mu \mathrm{s}$ after the start of injection at flashing conditions.

As visible in Figs. 2 and 3, at subcooled conditions the main spray characteristics such as jet penetration and cone angle are well represented by the simulations; as for the flashing operating point, it is possible to state that there is a slight overestimation of the cone angle value even if the global morphology of the spray is well predicted. To quantitatively validate the numerical framework, a comparison between numerical and experimental liquid penetration curves is reported in Fig. 4.

\section{Subcooled Condition}

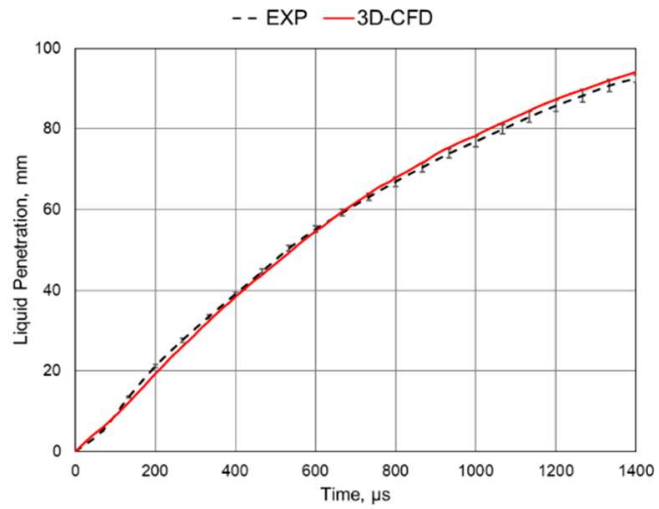

(a)

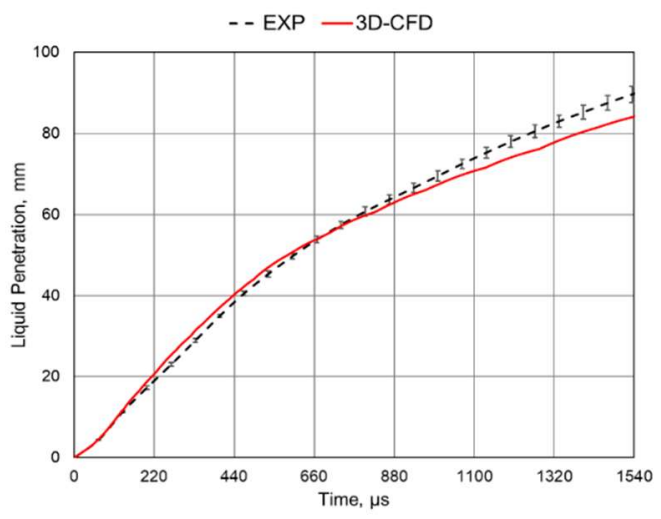

(b)

Fig.4. Liquid penetration comparison for (a) subcooled and (b) flashing cases.

It is useful to point out that, on the numerical side, the maximum penetration is considered for the comparison. In other words, the distance along the injector axis between the farthest droplet and the tip is reported in Fig. 4. Error bars are shown in the experimental curves to point out the standard deviation values. Numerical liquid 
penetrations closely reproduce experimental results in both cases; a slight underestimation of the penetration in the last stage of the injection is reported for the flashing case, due to the previously commented overestimation of the cone angle. Since a reduction of the droplet size is expected when flash boiling occurs, the last comparison is carried out in terms of PDA data. PDA analysis is carried out along the nozzle axis at $20 \mathrm{~mm}, 30 \mathrm{~mm}, 40$ $\mathrm{mm}$, and $50 \mathrm{~mm}$ far from the injector tip; comparisons between numerical and experimental mean droplet diameter (D10) and velocity magnitude are depicted in Figs. 5 and 6. It can be seen that both D10 and velocity values are well predicted by the numerical simulations at all the measurement stations; it is useful to point out that PDA values are filtered in specific time interval with the aim to analyze the characteristics of the spray in the static phase of the injection. As for the flashing case, the adopted model is able to predict the reduction of droplet diameters due to flashing along the axial direction.

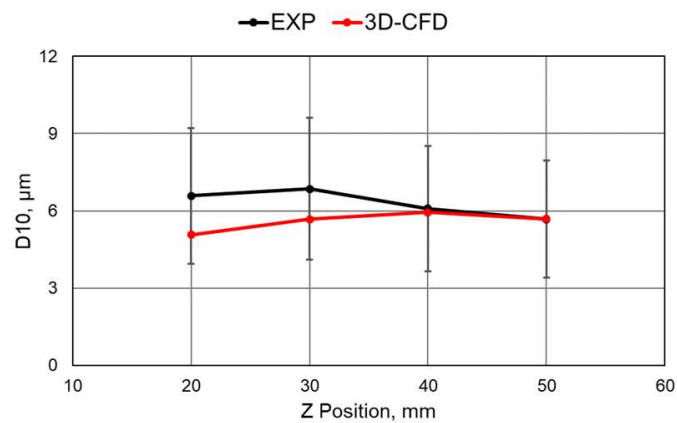

(a)

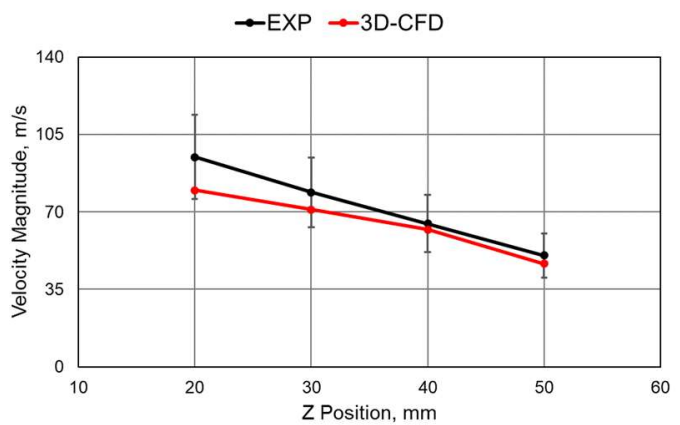

(b)

Fig. 5. Comparison between simulations and experiments in terms of (a) D10 and (b) velocity magnitude at subcooled conditions.

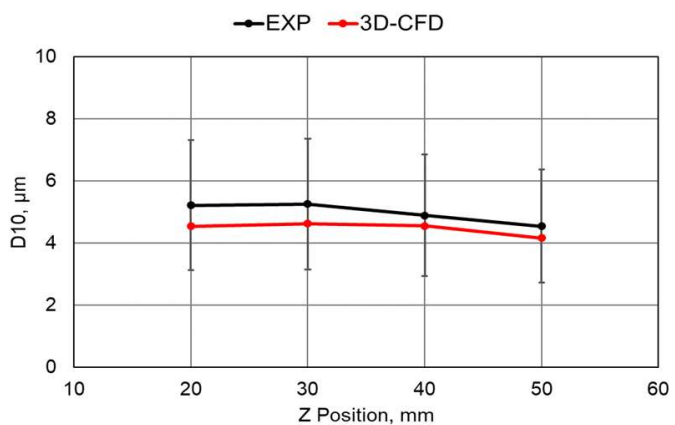

(a)

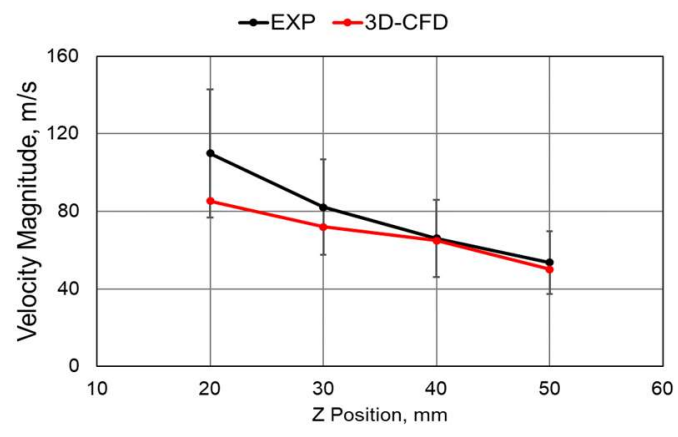

(b)

Fig. 6. Comparison between simulations and experiments in terms of (a) D10 and (b) velocity magnitude at flashing conditions. 


\section{CONCLUSIONS}

In the present paper, a validation of a flash boiling model to be adopted in ALE simulations, implemented in the last version of the commercial code STARCD, is performed on a single-hole research injector. Numerical results are validated against experimental outcomes provided by SprayLAB of Perugia University; a methodology to evaluate droplets initial conditions based on experimental momentum measurements is depicted. The main conclusions of this work can be drawn as follows:

- $\quad$ experimental momentum tests are very valuable to calculate droplet properties at the nozzle exit, such as initial diameter and initial velocity. Static values of mass flow rate and force on a target surface are exploited to evaluate the nozzle hydraulic coefficients, which are used as inputs for the Lagrangian simulations.

- for both subcooled and flashing conditions, numerical results show a good agreement with experimental data, in terms of imaging, liquid penetration and PDA data (D10 and velocity magnitude).

- $\quad$ as for the flash boiling atomization model, a slight overestimation of the cone angle in the flashing case can be noticed, according to the imaging comparison. This is confirmed by the penetration curves where, in the flashing case, a slight underestimation of the liquid length emerges.

- as demonstrated by the comparison between numerical and experimental values of D10, the flash boiling breakup model is able to predict the reduction of droplets size along the envelope of the spray due to vapor bubble nucleation and burst inside the liquid droplets.

\section{ACKNOWLEDGMENTS}

The authors would like to thank the SprayLAB of Perugia University for providing experimental measurements and SIEMENS PLM for granting licenses.

\section{REFERENCES}

1. V. Mangeruga, M. Giacopini, S. Barbieri, F. Berni et al., SAE Int. J. Adv. \& Curr. Prac. in Mobility 2(2):721-736, 2020, doi.org/10.4271/2019-24-0197

2. L. Teodosio et al., AIP Conference Proceedings, 2191, art. no. 020147, (2019), doi.org/ $10.1063 / 1.5138880$

3. L. Teodosio, V. De Bellis, F. Bozza, D. Tufano, SAE Technical Paper 2017-24-0015, 2017, doi.org/10.4271/2017-24-0015

4. E. Severi et al., Energy Procedia, 81, pp. 846-855, (2015), doi.org/10.1016/j.egypro.2015.12.094

5. C. Tornatore et al., Energy, 172: p. 968-976, 2019, doi.org/10.1016/j.energy.2019.02.031

6. F. Berni et al., Energy Procedia, 81, pp. 826-835, (2015), doi.org/10.1016/j.egypro.2015.12.091

7. F. Berni, S. Breda, A. D'Adamo, S. Fontanesi et al., SAE Technical Paper 2015-24-2499, 2015, doi.org/10.4271/2015-24-2499

8. A. d'Adamo, F. Berni, S. Breda, M. Lugli et al., SAE Technical Paper 2015-01-0393, 2015, doi.org/10.4271/2015-01-0393

9. S. Breda et al., Energy Procedia, 82, pp. 96-102, (2015), doi.org/10.1016/j.egypro.2015.11.888

10. Teodosio, L., et al., "Impact of intake valve strategies on fuel consumption and knock tendency of a spark ignition engine" (2018) Applied Energy, 216, pp. 91-104. DOI: 10.1016/j.apenergy.2018.02.032

11. A. Montanaro, L. Allocca, Droplet Interactions and Spray Processes. Fluid Mechanics and Its Applications, vol 121. Springer, Cham., 2020, doi.org/10.1007/978-3-030-33338-6_24 
12. A. d'Adamo et al., Applied Energy, 249, pp. 126-142, 2019, doi.org/10.1016/j.apenergy.2019.04.093

13. A. Rosetti et al., SAE Technical Papers, 2019, art. no. 0006, doi.org/10.4271/2019-24-0006

14. A. D'Adamo et al., SAE International Journal of Engines, 10 (3), 2017 doi.org/10.4271/2017-010551

15. A. d'Adamo et al., Applied Energy, Volume 191, 2017, Pages 251-263, doi.org/10.1016/j.apenergy.2017.01.101

16. S. Breda et al., SAE Int. J. Engines 9(1):641-656, 2016, doi.org/10.4271/2016-01-0601

17. S. Fontanesi et al., Energy Procedia, Volume 45, 2014, Pages 769-778, doi.org/10.1016/j.egypro.2014.01.082

18. V.L. Krastev et al., International Journal of Engine Research, 21 (4), pp. 632-648, 2020, doi.org/10.1177/1468087419851905

19. F. Berni et al., Applied Thermal Engineering, 174, 2020, doi.org/10.1016/j.applthermaleng.2020.115320

20. F. Berni et al., AIP Conference Proceedings, 2191, art. no. 020019, 2019, doi.org/10.1063/1.5138752

21. G. Cicalese et al., SAE Technical Paper 2017-01-2196, 2017, doi.org/10.4271/2017-01-2196

22. F. Berni et al., Applied Thermal Engineering, 115, pp. 1045-1062, 2017, doi.org/10.1016/j.applthermaleng.2017.01.055

23. G. Cicalese, F. Berni, S. Fontanesi, SAE Int. J. Engines 9(1):601-617, 2016, doi.org/10.4271/2016-01-0578

24. F. Berni et al., SAE International Journal of Commercial Vehicles, 10 (2), 2017, doi.org/10.4271/2017-01-0569

25. M. Del Pecchia et al., Fuel, 264, art. no. 116741, 2020, doi.org/10.1016/j.fuel.2019.116741

26. A. D'Adamo, M. Del Pecchia, S. Breda, F. Berni et al., SAE Technical Paper 2017-01-2190, 2017, doi.org/10.4271/2017-01-2190

27. S. Malaguti et al., SAE Technical Paper 2009-01-0704, 2009, doi.org/10.4271/2009-01-0704

28. S. Malaguti et al., SAE Technical Paper 2010-01-2123, 2010, doi.org/10.4271/2010-01-2123

29. S. Breda et al., Fuel, 243, pp. 104-124, 2019, doi.org/10.1016/j.fuel.2019.01.111

30. S. Nagumo, S.Hara, JSAE Rev., vol. 16, pp. 13-19, 1995, doi.org/10.1016/0389-4304(94)00048$\mathrm{X}$

31. P. Aleiferis et al., Combustion and Flame, Vol. 157 (4), 735-756, 2010, doi.org/10.1016/j.combustflame.2009.12.019

32. M. Xu et al., SAE Int. J. Fuels Lubr., Vol. 6 (1), 137-148, 2013, doi.org/10.4271/2013-01-1614

33. W. Shengqi, M. Xu et al., ILASS Americas 25th Annual Conference, Pittsburgh, PA, May 2013

34. P. Aleiferis et al., Fuel Vol. 105, 143-168, 2013, doi.org/10.1016/j.fuel.2012.07.044

35. E. Sher et al., Progress in Energy and Combustion Science, Vol 34 (4), 417-439, 2008.

36. P. Aleiferis, et al., International Journal of Heat and Mass Transfer, vol. 53, 4588-4606, 2010, doi.org/10.1016/j.ijheatmasstransfer.2010.06.033

37. J. Serras-Pereira et al., "Cavitation, primary break-up and flash boiling of gasoline, iso-octane and n-pentane with a real-size optical direct-injection nozzle" Fuel, vol. 89, 2592-2607, 2010, doi.org/10.1016/j.fuel.2010.03.030

38. Siemens, Star-CD v. 2019.1 User Guide.

39. K.J. Wu, et al., The Physics of Fluids, 1986. 29(4): p. 941-951, doi.org/10.1063/1.865689

40. S. Sparacino et al., Energies 2019, 12, 2890, doi.org/10.3390/en12152890

41. S. Sparacino, F. Berni, A. Cavicchi, L. Postrioti. AIP Conference Proceedings, 2191, art. no. 020139, 2019 doi.org/10.1063/1.5138872

42. A. Cavicchi et al., Fuel, Volume 263, 2020, 116657, ISSN 0016-2361. doi.org/10.1016/j.fuel.2019.116657

43. A. Cavicchi, S. Sparacino, F. Berni, L. Postrioti, S. Fontanesi. AIP Conference Proceedings, 2191, art. no. 020043,2019 , doi.org/10.1063/1.5138776

44. C. Price et al., Atomization and Sprays, 26 (12) pp. 1197-1239, 2016 doi.org/10.1615/AtomizSpr.2016015807

45. C. Price et al., Fuel 221, pp.518-541, 2018, doi.org/10.1016/j.fuel.2018.01.088

46. J. Senda, ICLASS 2018, ID 432

47. M. Adachi et al., JSAE Review, vol. 17, pp. 231-237, 1996, doi.org/10.1016/03894304(96)00025-2 
48. J. Senda, Y. Hojyo, H. Fujimoto, SAE Technical Paper 941925, 1994, doi.org/10.4271/941925

49. L. Allocca et al., 2018, SAE International, doi.org/10.4271/2018-01-0306

50. Z. Han, R. D. Reitz, Combustion Science and Technology, 106:4-6, 267-295, 1995, doi.org/10.1080/00102209508907782

51. P.J. Linstrom et al., NIST Chemistry WebBook, 2017, National Institute of Standards and Technology.

52. L. Postrioti, L., et al., SAE Technical Paper 2018-01-0271, 2018, doi.org/10.4271/2018-01-0271

53. R. D. Reitz, R. Diwakar, SAE Transactions, vol. 95, 1986, pp. 218-227. JSTOR, www.jstor.org/stable/44725372 